\title{
Electron microscopical studies of vessels in diabetic peripheral neuropathy
}

\author{
ELUNED WILLIAMS, WR TIMPERLEY, JD WARD, AND T DUCKWORTH
}

From the Departments of Neuropathology and Medicine, The Hallamshire Hospital, Sheffield, UK

SUMMARY The results of an electron microscopical study of sural nerve biopsies from 11 patients with diabetic neuropathy are presented. Thrombi were seen in six cases in at least one intraneural vessel; nine cases showed hyperplasia of endothelial cells, and in seven out of these nine the hyperplasia was sufficient to occlude completely the lumen of small vessels; six cases showed degenerate pericytes and endothelial cells, and in some cases endothelial cells had been shed from the vessel wall, exposing the blood within the vessel to the underlying basement membrane; in five cases large lipid droplets were seen within endothelial cells. Abnormalities of the vessel wall would result in decreased fibrinolytic activity and a reduction of the antiplatelet aggregating properties of the vessel. Desquamation of endothelial cells from the vessel wall, with exposure of platelets to underlying collagen, may act as a trigger for thrombus formation, particularly as the blood of diabetic patients is often in a hypercoagulable state. The significance of hyperplasia of endothelial cells is at present unknown but, once established, this too would result in profound alterations of local blood flow and ischaemia of nerve. Damage to endothelial cells may also allow seepage of haematological constituents into the vessel wall, resulting in its progressive thickening.

Vascular abnormalities in sural nerve biopsies from patients with diabetic neuropathy were first described by Fagerberg. ${ }^{1}$ He described 'vascular lesions in the form of hyalinisation, caliber reduction and thickening of the wall which were more common in patients with diabetic neuropathy than in other groups'. He postulated a progressive degenerative disease which was responsible for the structural damage to the myelin sheath.

More recently, Timperley et al. ${ }^{2}$ demonstrated plugging of vessels with fibrin, infiltration of vessel walls by fibrin, occlusion of vessels by organising thrombus, and areas of necrosis in nerve bundles adjacent to degenerate or thrombosed vessels. It seems likely that thrombus formation in small vessels may be playing an important part in damage to diabetic nerves and that deposition of fibrin and thrombus followed by fibrinolysis and organisation could explain the phasic variation in symptoms sometimes seen in diabetic neuropathy.

We present the results of an electron microscopical study of a further series of sural nerve biopsies from patients with diabetic neuropathy and attempt to clarify some of the mechanisms by which abnormali-

Received for publication 29 October 1979 ties in small blood vessels and of the coagulation pathways may affect neural function in diabetics.

\section{Material and methods}

Sural nerve biopsies were carried out on 11 diabetic patients with evidence of neuropathy. Criteria for selection were based mainly on the presence of significant symptoms of neuropathy, since in our opinion these are easier to assess than physical signs. The clinical details of these patients are presented in three groups since there were similarities between some of the patients.

GROUP A : KETO-ACIDOTIC PATIENTS

(patients 1, 3, 4, 6, 7)

Four of these patients were insulin-dependent women aged 43 to 53 years who were admitted to hospital in diabetic keto-acidosis which required intensive fluid replacement and insulin therapy. Within four to six weeks of recovery all four of these patients complained of aching cramping sensations in the thighs and calves which subsided over a further four-week period. Sural nerve biopsy was performed in these patients at a time when they were symptomatic. The fifth patient was a 71-year-old man treated with chlorpropamide who was admitted in 
ketotic diabetic coma. Haematological investigation confirmed the presence of the diffuse intravascular coagulation syndrome. Profound weakness of the legs developed, and sural nerve biopsy was performed. Subsequent recovery was satisfactory.

\section{GROUP B : SEVERE MOTOR NEUROPATHY}

(patients $5,8,9$ )

These three men aged between 45 and 58 years all had severe chronic motor neuropathy affecting both arms and legs, and muscle wasting was prominent. In all three, the onset of this severe neuropathy occurred at times of very poor blood glucose control - two at diagnosis and one nine years after diagnosis. Only partial recovery of muscle power occurred.

GROUP C: MISCELLANEOUS

(patients 2,10,11)

Patient 2 was a woman aged 26. She had severe diabetic retinopathy with symptomatic sensory neuropathy in the legs, complicated by local gangrene of the toes and the presence of bounding foot pulses.

Patient 10, a 61-year-old woman, had a mixture of femoropopliteal obstruction and severe sensory neuropathy.

Patient 11, a man aged 70, had chronic neuropathic foot ulceration after years of motor-sensory symptoms in the legs.

Informed consent was obtained from patients undergoing nerve biopsy. No immediate or long- term complications have resulted from the procedure. The sural nerve was exposed under local anaesthesia behind the lateral malleolus. If the nerve was of sufficient thickness, which was usually the case, it was split, and a 1.5 to $2 \mathrm{~cm}$ length was taken from one half, leaving the nerve in functional continuity.

After removal the nerve was handled gently with forceps, and the nerve was cut transversely into $1 \mathrm{~mm}$ lengths which were fixed in $2.5 \%$ glutaraldehyde in $0.1 \mathrm{M}$ phosphate buffer $(\mathrm{pH} \mathrm{7.35)}$ for 1 hour at room temperature with constant agitation. The pieces of nerve were then carefully trimmed to remove epineural fat and excess connective tissue and were separated into individual fascicles. They were then placed in fresh glutaraldehyde and fixed for a further hour. Afterwards they were washed several times in $0.1 \mathrm{M}$ phosphate buffer $(\mathrm{pH} 7 \cdot 35)$ and post-fixed in $1 \%$ osmium tetroxide at room temperature for 1 hour with constant agitation. The nerve was then washed in phosphate buffer and finally rinsed in distilled water. After dehydration the tissue was embedded in epoxy resin.

Samples of sural nerve were also examined from 10 controls: three were traumatic amputation specimens (aged 29, 37, and 53); one was an amputation specimen from a patient aged 21 with a sarcoma of the leg being treated with cytotoxic therapy; one was from a patient aged 49 with alcoholic neuropathy; three were from fresh necropsies (aged 63, 47, and 60 ); and one was a sural nerve biopsy from a man aged 32 with an hereditary neuropathy.

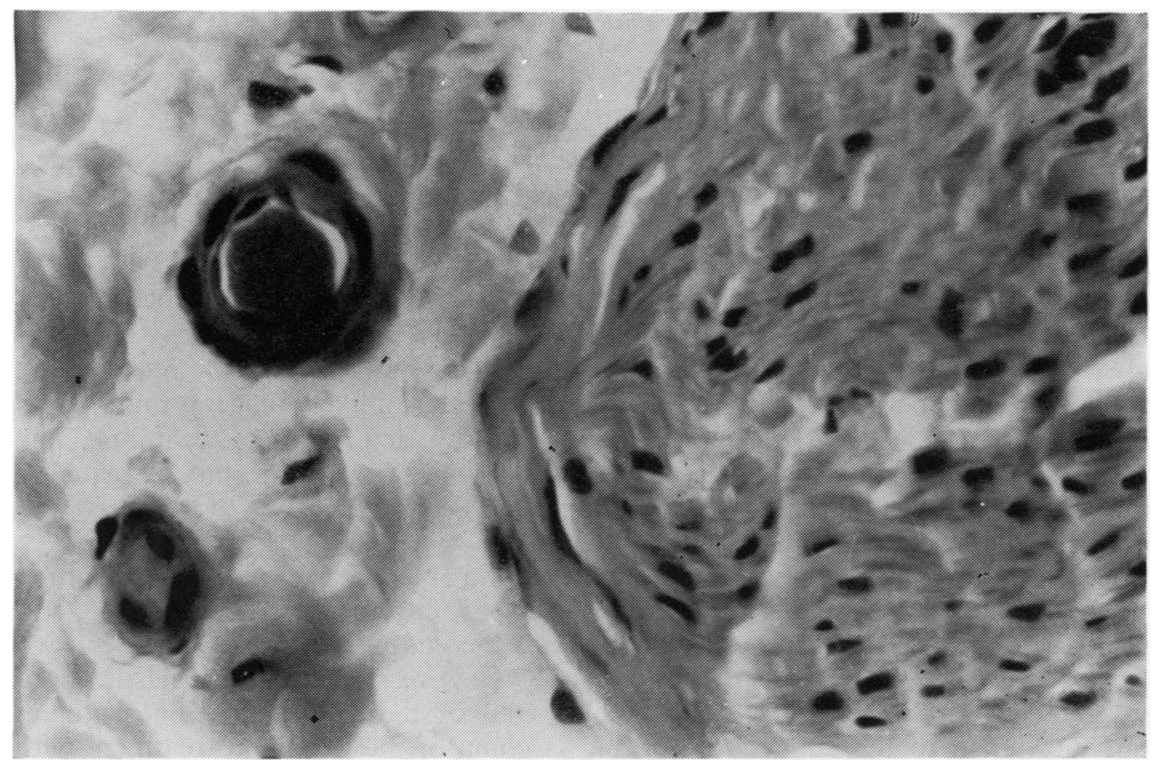

Fig. 1 Transverse section of a sural nerve biopsy from a diabetic patient showing a ball of fibrin in a small blood vessel to the right of a nerve bundle. Haematoxylin and eosin stain. $\times 600$. 


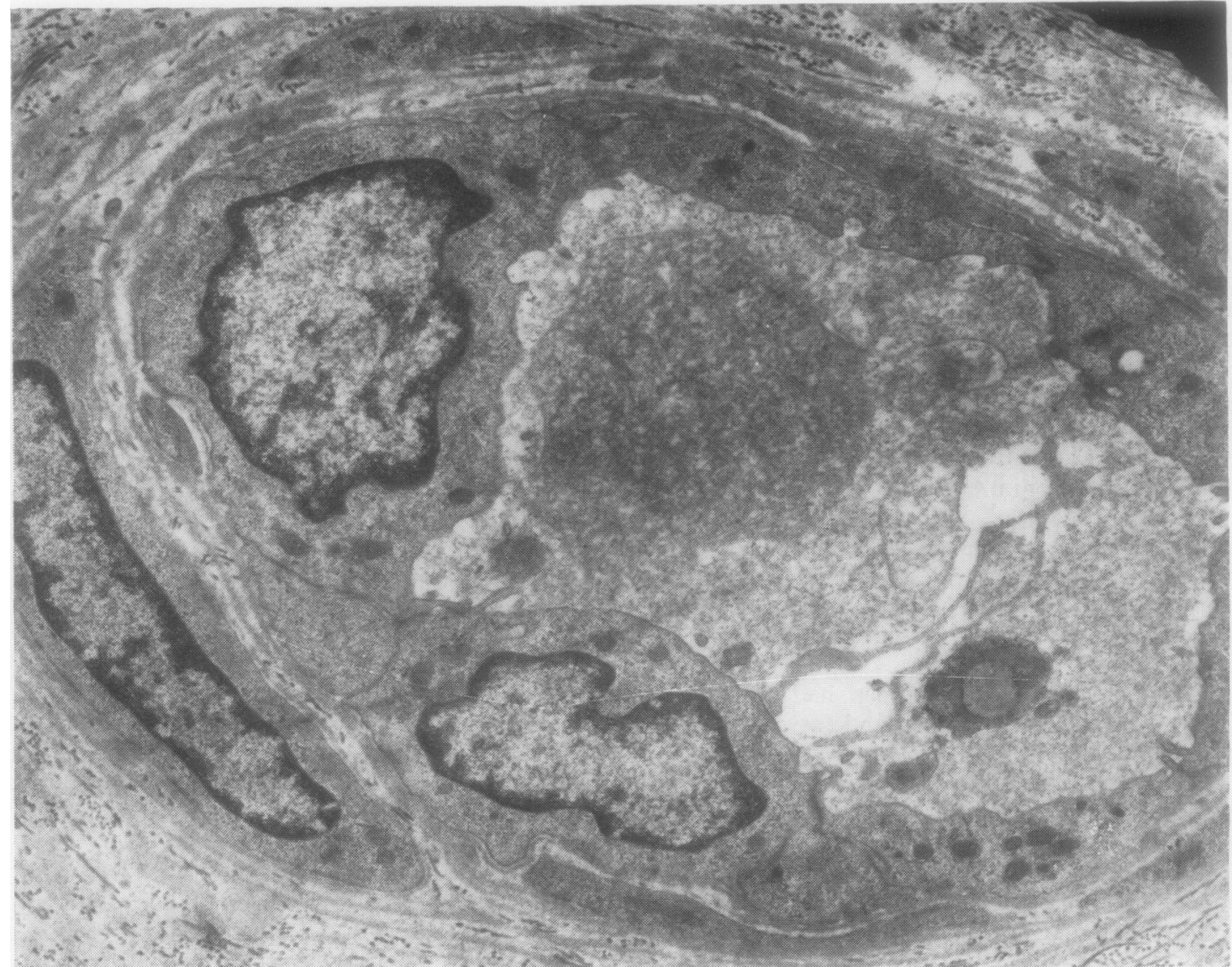

Fig. 2 Electron microscopical picture of a small blood vessel in a sural nerve biopsy of a diabetic patient showing a ball and strands of fibrin within the lumen. $\times 6300$.

\section{Results}

Six out of 11 cases showed thrombi in at least one intraneural vessel (cases $1,3,5,6,7,10$ ). In some small vessels masses of fibrin were seen within the lumen (Figs 1 and 2). In other vessels older thrombus was present (Figs 3 and 4).

Nine out of the 11 cases showed hyperplasia of endothelial cells in some vessels (cases $2,3,5,6,7,8$, $9,10,11$ ), and in seven out of these nine cases (cases $5,6,7,8,9,10,11)$ the degree of hyperplasia was sufficient to occlude the lumen of the vessel completely (Fig. 5).

Six out of the 11 cases showed degenerate pericytes and endothelial cells in some vessels (cases 1, 3, 5, 6, 7,10 ), and in the more severely affected vessels the endothelial cells had been shed from the vessel wall, exposing the blood within the lumen to the colla- genous basement membrane (Fig. 6). Less affected vessels showed marked pyknosis of endothelial cell and pericyte nuclei, and many of the endothelial cells contained large lipid droplets (Fig. 3).

In all the cases showing evidence of hyperplasia of endothelial cells, other capillaries lined by endothelial cells of normal size and thickness were also seen. In view of this, it seems unlikely that this finding was detailed ultrastructure of the intracellular organelles and of the nuclei of these cells were also well preserved.

Among the controls, no cases contained thrombi, degenerate vessels, degenerate pericytes, or lipid droplets within the endothelial cells. However, two cases did show a few vessels with hyperplastic endothelial cells. One of these was a patient with an osteogenic sarcoma of the femur on treatment with related to the biopsy or processing technique. The 


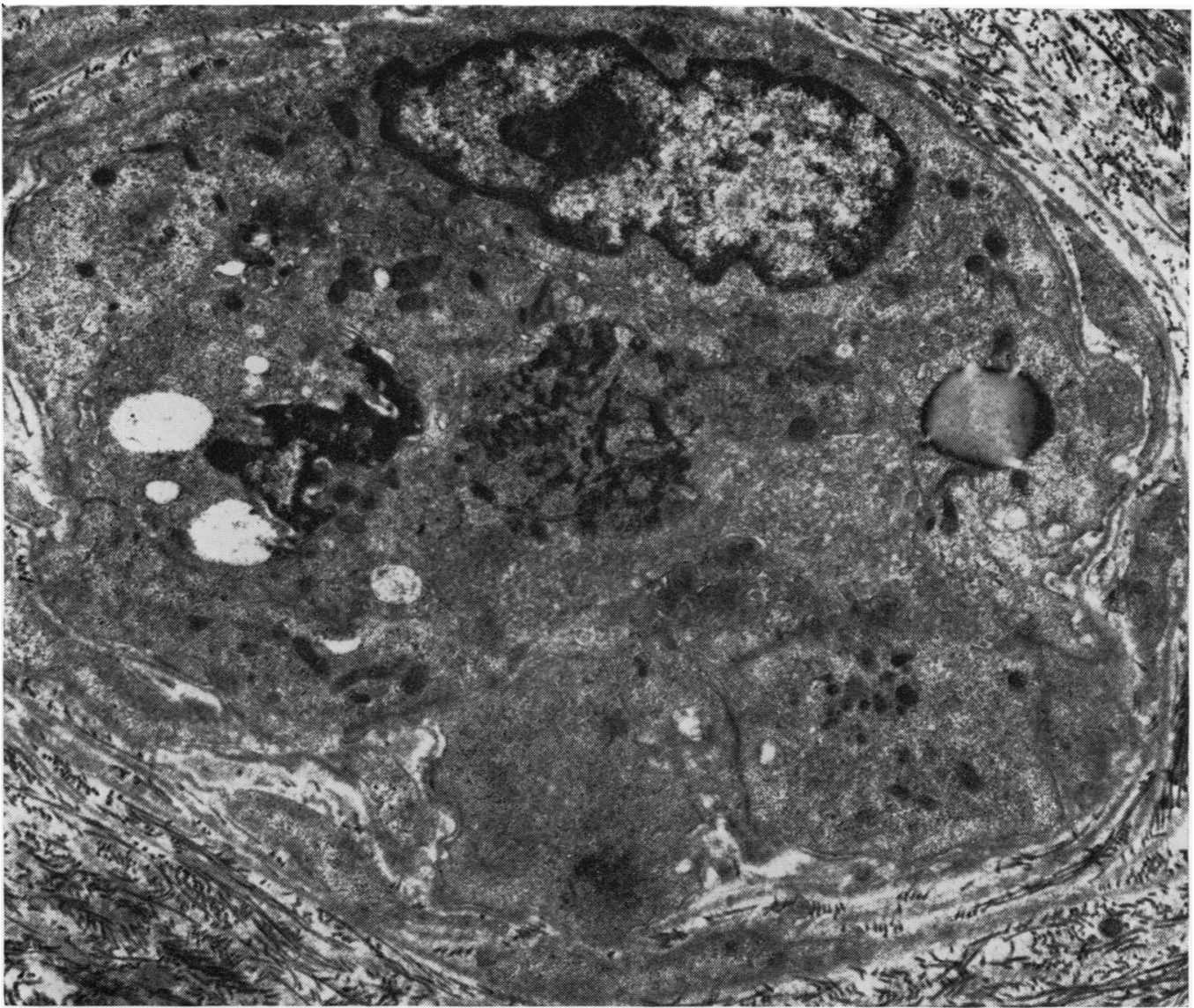

Fig. 3 Electron microscopical photograph of a vessel occluded by thrombus containing both degenerate cells and fibrin. Note that the endothelial cells of the vessel also appear somewhat degenerate, and within one of them a large lipid droplet can be seen.

high doses of cytotoxic drugs, and the other was a man aged 49 with alcoholic neuropathy and hypertension.

\section{Discussion}

Several abnormalities have now been described in small blood vessels in diabetics. As long ago as 1929, Woltman and Wilder ${ }^{3}$ described widespread thickening in the walls of intraneural vessels and thought that arteriosclerosis was the cause of diabetic neuropathy. A more detailed and more comprehensive study was carried out by Fagerberg, ${ }^{1}$ who described thickening and hyalinisation of walls of intraneural vessels in a series of sural nerve biopsies and sural nerves removed at necropsy. Thickening was due to accumulation of PAS-positive material. Similar changes were described in the vessels of autonomic nerves by Olsson and Sourander. ${ }^{4}$ Thickening of the basement membrane around capillaries of intraneural diabetic vessels was confirmed electron microscopically by Bischoff $^{5}$ and Lapresle. ${ }^{6}$

Anderson ${ }^{7}$ postulated that the nodular lesion in diabetic glomerulosclerosis was a result of fibrin deposition or some other protein substance, and Lendrum $^{8}$ thought that the nodules were derived from fibrin which underwent a change to 'pseudocollagen'. Larsson ${ }^{9}$ and Westberg and Michael ${ }^{10}$ demonstrated fibrin, globulins, and albumin in the glomerular basement membranes of diabetics, and Farquar $^{11}$ demonstrated fibrinogen and fibrin in affected glomeruli electron microscopically and with immunofluorescent techniques. She postulated that the thickening of the basement membrane could 


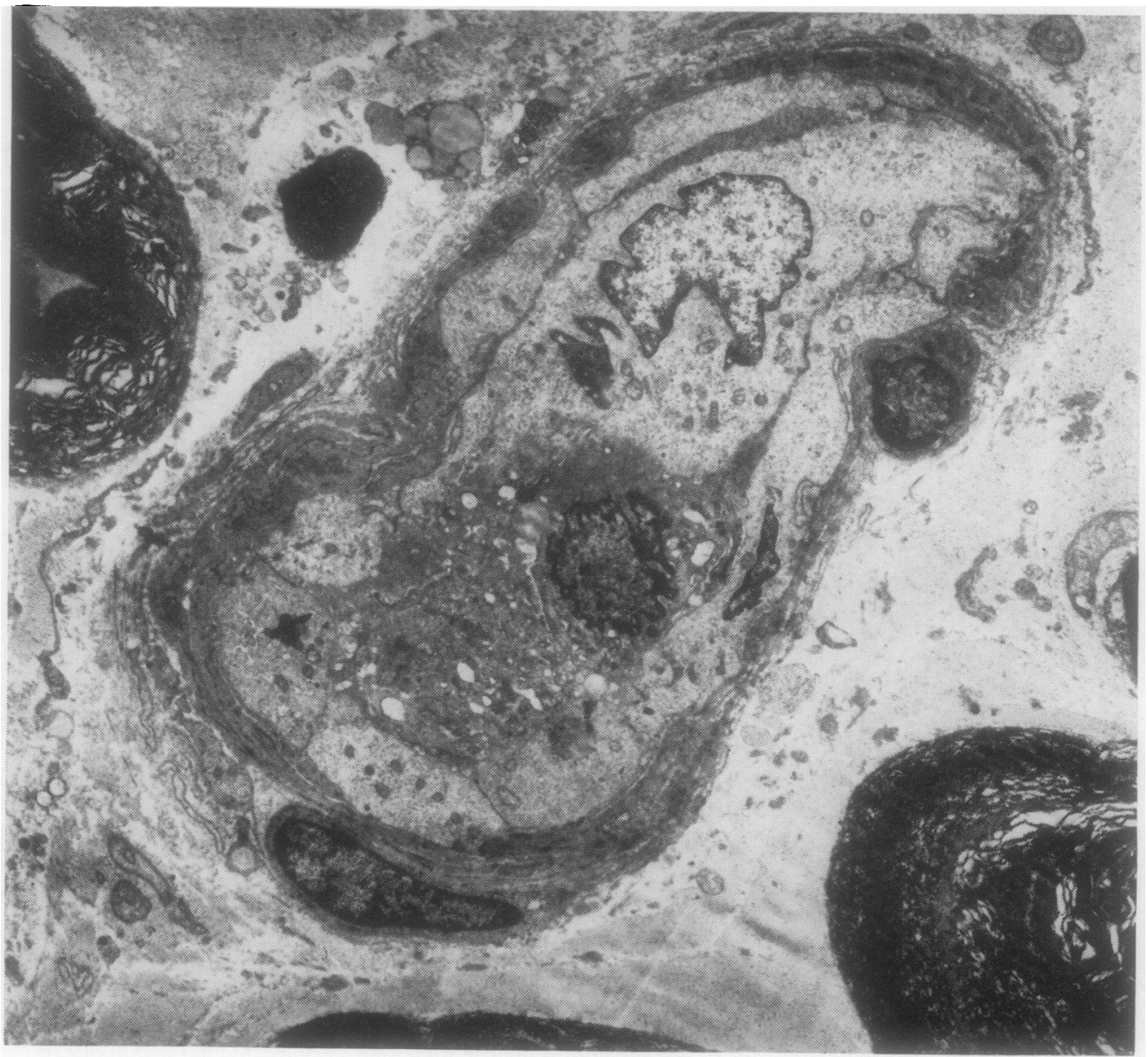

Fig. 4 Electron microscopical picture of a vessel occluded by thrombus containing a mixture of fibrin and degenerate cellular elements. $\times 4000$.

result from penetration of a variety of haematological elements, including plasma, fibrin, red cells, and platelets, into the wall of retinal vessels.

Similarly, Ashton, ${ }^{12}$ in an electron microscopical study of diabetic retinopathy, demonstrated disruption of vascular endothelial cells and marked laminated thickening in the region of the basement membrane due to fine granular and fibrillar material indistinguishable from basement membrane, containing cholesterol crystals, lipid, and red cell fragments. This was clear evidence of vascular leakage through the retinal endothelial barriers. The appearances suggested that the potential spaces between the vessel wall and the investing glia had opened to contain this heterogeneous leaking material which gradually flows between the glial cells to form exudates. Ashton also pointed out that the demonstration of insulin-anti-insulin complexes within the basement membrane ${ }^{1314}$ is more likely to be due to nonspecific haematogenous deposition and further evidence of abnormal endothelial permeability. He postulated that diabetic retinopathy is in the main an ischaemic condition due to chronic fibrinous vasculosis affecting the vessel wall, resulting in intraneural leakage.

Examination of the colour photographs in Fagerberg's paper led us to believe that some of the material staining with the PAS stain was possibly on the luminal side of the endothelial cell as well as within the wall of the vessel, and that this could be 


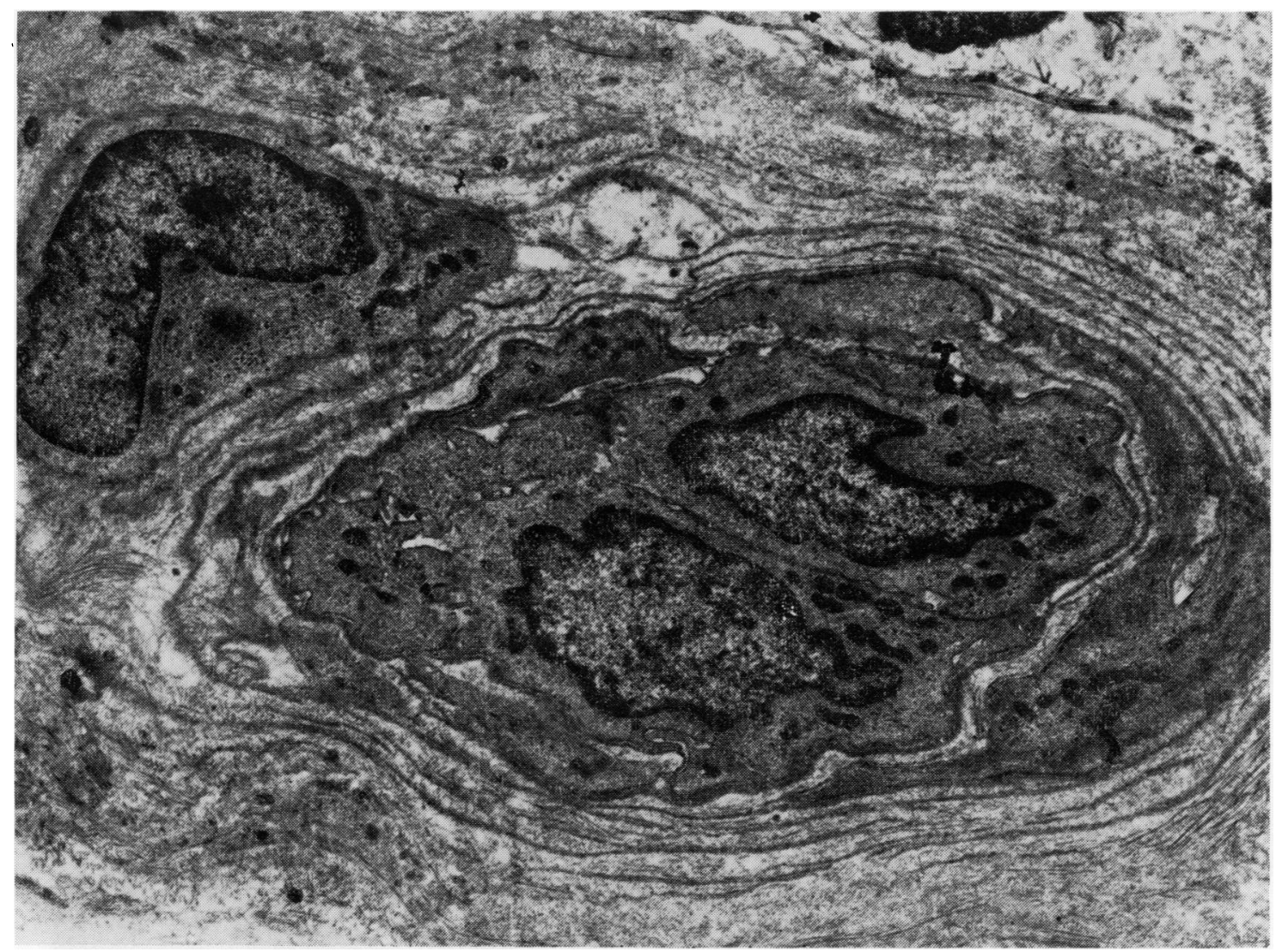

Fig. 5 Electron microscopical picture of a small vessel in a sural nerve biopsy from a diabetic patient showing occlusion of lumen by hyperplastic endothelial cells. $\times 4000$.

fibrin. In a light-microscopical study of sural nerve biopsies, Timperley et al. ${ }^{2}$ demonstrated plugging of vessels with fibrin and penetration of fibrin into the vessel wall in some cases. Some vessels also contained older thrombus, and areas of necrosis within the nerve were also demonstrated in some biopsies. It seems likely that a disturbance in the balance between deposition and removal of fibrin by fibrinolysis is playing some part in damage to diabetic nerves and that variations in the ability to clear the deposited fibrin could explain the phasic variation in symptomatology sometimes seen in diabetic neuropathy. Examination of the thrombi in some of these vessels showed that there were aggregates of granular material within the thrombus and it seemed likely that these were platelet aggregates.

Abnormalities of platelet function in patients with diabetic neuropathy have been demonstrated on a number of occasions. O'Malley et al. ${ }^{15}$ showed that platelets from patients with diabetic neuropathy were extremely senstive to low concentrations of the platelet-aggregating agents, ADP and adrenaline. Similarly, patients with diabetic microangiopathy were found to have increased numbers of circulating platelet aggregates. ${ }^{16}$ The latter authors were also able to demonstrate increased levels of the plateletspecific protein, beta-thromboglobulin, in the plasma of diabetics, particularly in those with evidence of microangiopathy. An interesting aspect of this study is that the levels of beta-thromboglobulin were also raised in new diabetics and that the levels returned to normal several weeks after therapy. This suggests that abnormalities of platelet function occur early in the course of diabetes and are not necessarily a result of the angiopathy itself.

Ferguson et al. ${ }^{17}$ demonstrated shortened platelet and fibrinogen survival time in diabetic patients, and Garg et al. ${ }^{18}$ showed that diabetic patients have an 


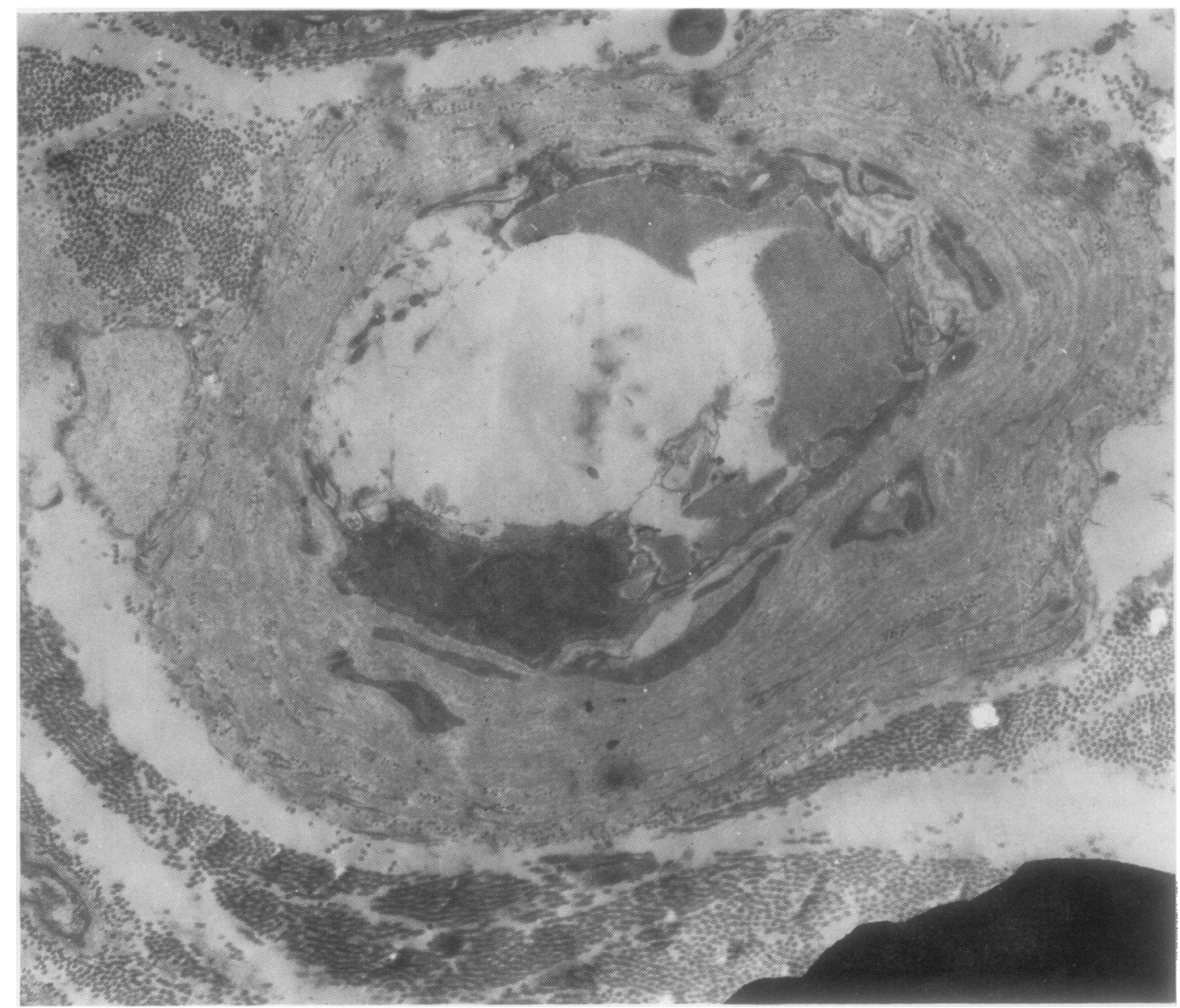

Fig. 6 Electron microscopical picture of a small blood vessel in a sural nerve biopsy of a diabetic patient showing marked thickening of the wall and severe degenerative changes within the endothelial cells, some of which have been shed, resulting in exposure of blood within the vessel to the collagenous basement membrane.

increased number of megathrombocytes in the blood; since megathrombocytes are thought to be young platelets, this probably indicates increased platelet turnover.

The results of the present study show several features of interest. Six cases showed evidence of fibrin formation within at least one vessel. In some cases the lumen of the vessel was totally occluded, and in others masses of fibrin could be seen within the lumen. In some vessels older thrombus was seen. Nine out of 11 cases showed hyperplasia of endothelial cells with complete obliteration of the lumen of the vessel in some vessels. Five cases showed large lipid droplets within endothelial cells, and six showed vessels with degenerate pericytes. In cases showing the most severe evidence of degeneration of vessels, the endothelium had completely disappeared in parts, leaving a tube of basement membrane through which blood was flowing. Similar basement membrane tubes have been described in the retina. ${ }^{19}$ It is possible that these tubes could trigger off local thrombus formation by direct contact of blood with collagen, a potent platelet-aggregating agent.

The presence of capillaries with hyperplastic endothelial cells, sometimes resulting in complete obliteration of the lumen of a capillary, is of considerable interest since this could seriously affect blood flow to parts of a nerve. The reason why some capillaries have an increased complement of endothelial cells is not known. This abnormality has been described in digest preparations of retina in patients with diabetic retinopathy where there are many capillaries with 
more than the normal complement of endothelial cells; these abnormalities are often associated with degenerative changes in pericytes or complete absence of these cells. ${ }^{20}$ In a correlative study between digest preparations and fluorescence angiograms, Kohner and Henkind ${ }^{19}$ suggested that the hypercellularity is a feature of dilated capillaries, and that the increased intravascular pressure may stimulate endothelial cell proliferation as it does in collaterals after branch vein occlusion. In view of the fact that some vessels with hyperplastic endothelial cells were found in two of our controls, it seems unlikely that it is directly due to the diabetes but may be related to some local metabolic change. Similar hyperplastic endothelial cells have been described in hypertension. ${ }^{21}$ It is of interest that one of our two controls showing this abnormality was also hypertensive. The other control showing this abnormality had an osteogenic sarcoma of the femur with venous congestion of the lower limb, and the patient was also being treated with cytotoxic drugs. Further work needs to be done on this aspect of small vessel function.

Degeneration of pericytes is probably just one aspect of a more generalised degenerative vascular disease; it is commonly associated with degenerative changes within vascular endothelial cells or with areas of the capillary that have lost their endothelial cell lining completely. Cogan and Kuwabara ${ }^{22}$ suggest that the pericytes of the capillary wall act like smooth muscle cells, maintaining vascular tone, and that degeneration or loss of these cells results in dilatation of the vessels and possibly aneurysm formation.

In summary, there are clearly many ways in which abnormalities of the coagulation mechanisms and of the blood vessels themselves can result in severe disturbances of neural function in diabetics. The results of this study show that fibrin formation within the lumen of capillaries is occurring in diabetics, and the fact that it was demonstrated in six out of our 11 cases implies that it is a common event. It is even more remarkable that it was seen so frequently in a small proportion of the total length of a nerve. Damage to a nerve anywhere along its course from the spinal cord to the periphery would be sufficient to account for disturbance of function; thrombus formation sufficient to result in infarction and necrosis of nerve tissue would damage the nerve permanently. Degenerative changes within endothelial cells and pericytes would affect transport of nutrients between the blood and the adjacent tissues and the flow characteristics of blood through the vessel. Damage to endothelial cells may affect fibrinolytic activity and the ability of the vessel to prevent platelets aggregating, since the antiplatelet aggregating agent, prostacyclin-X, is known to be associated with endothelial cells. Damage to endothelial cells may also allow seepage of haematological constituents into the vessel wall, resulting in its progressive thickening. Exposure of blood to collagen beneath the endothelial cells would act as a trigger for platelet aggregation and local thrombus formation.

We are indebted to the British Diabetic Association and to the endowment funds of the Trent Region Health Authority (Teaching) (grant code number 230) for the provision of financial support. We also thank Mrs Pamela Kirk for typing the manuscript.

\section{References}

${ }^{1}$ Fagerberg SE. Diabetic neuropathy, a clinical and histological study on the significance of vascular affections. Acta Med Scand 1959;164 (Suppl 345); 1-97.

2 Timperley WR, Ward JD, Preston FE, Duckworth T, O'Malley BC. Clinical and histological studies in diabetic neuropathy. A reassessment of vascular factors in relation to intravascular coagulation. Diabetologia 1976; 12:237-43.

${ }^{3}$ Woltman HW, Wilder RM. Diabetes mellitus; pathologic changes in the spinal cord and peripheral nerves. Arch Int Med 1929;44:576-603.

${ }^{4}$ Olsson Y, Sourander P. Changes in the sympathetic nervous system in diabetes mellitus. $J$ Neurovisc Rel 1968;31:86-95.

${ }^{5}$ Bischoff A. Diabetische Neuropathie: pathologische Anatomie, Pathophysiologie und Pathogenese auf Grund elekronenmikroskopisher Untersuchungen. Dtsch Med Wochenschr 1968;93:237-41.

${ }^{6}$ Lapresle J. Étude anatomique des neuropathies périphériques du diabète sucré. Journ Annu Diabetol Hôtel Dieu 1968;9:101-13.

${ }^{7}$ Anderson GS. The pathogenesis of diabetic glomerulosclerosis. J Path Bact 1954;67:241-5.

${ }^{8}$ Lendrum AC. The validation of fibrin, and its significance in the story of hyalin. In: Signy G Trends in Clinical Pathology: Essays in Honour of G Signy. London: British Medical Association, 1969:159-87.

${ }^{9}$ Larsson O. Studies of small vessels in patients with diabetes. Acta Med Scand 1967;183 (Suppl 480), 5-66.

10 Westberg NG, Michael AF. Immunohistopathology of diabetic glomerulosclerosis. Diabetes 1972;21:163-74.

${ }^{11}$ Farquar MG. Glomerular permeability investigated by electron microscopy. In: Siperstein MD, Colwell AR, Meyer K, eds. Small Blood Vessel Involvement in Diabetes Mellitus. Washington: American Institute of Biological Sciences, 1964;235-43.

${ }^{12}$ Ashton N. Vascular basement membrane changes in diabetic retinopathy. Br J Ophthalmol 1974;58:34466.

${ }^{13}$ Freedman P, Peters JH, Kark RM. Localization of gamma-globulin in the diseased kidney. Arch Int Med 1960;105:524-35. 
${ }^{14}$ Berns AW, Owens CT, Hirata Y, Blumenthal HT. The pathogenesis of diabetic glomerulosclerosis. II. A demonstration of insulin-binding capacity of the various histopathological components of the disease by fluorescence microscopy. Diabetes $1962 ; 11: 308-17$.

${ }^{15}$ O'Malley BC, Timperley WR, Ward JD, Porter NR, Preston FE. Platelet abnormalities in diabetic peripheral neuropathy. Lancet 1975;2:1274-8.

${ }^{16}$ Preston FE, Ward JD, Marcola BH, Porter NR, Timperley WR. Elevated beta-thromboglobulin levels and circulating platelet aggregates in diabetic microangiopathy. Lancet $1978 ; 1: 238-40$.

${ }^{17}$ Ferguson JC, Mackay N, Philip JAD, Sumner DJ. Determination of platelet and fibrinogen half-life with [75 Se] selenomethionine: studies in normal and diabetic subjects. Clin Sci Mol Med 1975;49:115-20.

${ }^{18}$ Garg SK, Lackner H, Karpatkin S. The increased percentage of megathrombocytes in various clinical disorders. Ann Int Med 1972;77:361-9.
${ }^{19}$ Kohner EM, Henkind P. Correlation of fluorescein angiogram and retinal digest in diabetic retinopathy. Am J Ophthalmol 1970;69:403-14.

20 Ashton N. Studies of the retinal capillaries in relation to diabetic and other retinopathies. $\mathrm{Br} J$ Ophthalmol 1963;47:521-38.

${ }^{21}$ Shortland J. The fine structure of renal arteries in experimental hypertension. PhD thesis, University of Sheffield.

${ }^{22}$ Cogan DG, Kuwabara T. Capillary shunts in the pathogenesis of diabetic retinopathy. Diabetes 1963: 12:293-300.

Requests for reprints to: Dr W R Timperley, Department of Neuropathology, Floor N, Hallamshire Hospital, Glossop Rnad, Sheffield S10 2JF, UK. 